\title{
Supporting the mental health needs of young people: The spatial practices of school nurses.
}

\section{Dr. Sarah SherwinＥmail: Sarahsherwin3@gmail.com}

\begin{abstract}
Purpose

The purpose of this paper is to raise awareness of an understanding of how school nurses work in multiple spaces, supporting young people in relation to promoting and protecting their emotional and mental health and wellbeing. It is argued that young people's emotional health needs are still as prevalent today as they were over 150 years ago, when Charles Dickins wrote about them in the novel Nicholas Nickleby.
\end{abstract}

\section{Design/methodology/approach}

Soja's (1996) typology of spatial practice is applied to school nursing practice in an attempt to explore how different types of space influence how support is given to young people.

\section{Findings}

Examples are provided from previous research (Sherwin, 2016) of how Soja's theory of Firstspace, Secondspace and Thirdspace can be identified within school nurses' practice, thereby providing an understanding of how school nurses provide support to young people on an everyday basis. It is proposed that in an addition Fourthspace also exists and a new conceptual model of spatial practice is proposed. 


\section{Originality/value}

School nurses have the potential to make a significant impact on preventing and protecting young people's mental health. They provide valuable support to young people to enable them to cope with the complexities of their lives, yet relatively little is known about their everyday practice as this is an under reported area of nursing. A new conceptual model is proposed to help provide an understanding of their practice.

\section{Key words:- school nursing, emotional health, young people, spatial practice}

\section{Introduction}

"What happens when the light first pierces...the dark dampness in which we have waited? We are slapped and cut loose. If we are lucky someone is there to catch us.... and persuade us that we are safe. But are we safe? What happens if, too early we lose a parent? That party on whom we rely for not only everything? Why, are we cut loose again ... and we wonder, even dread...whose hands will catch us now?"1

The importance of providing support to those that are in distress or crisis, is as essential today as it was back in 1839 , when Charles Dickens wrote about it in his novel Nicholas Nickleby. Indeed, the prevalence of mental health issues in young people is an increasing concern (Ravenna and Cleaver, 2016; PHE, 2018), with 50\% of all adult mental disorders commencing during adolescence (Hagell, Coleman and Brooks, 2015). Addressing emotional wellbeing in young people is one of six high impact areas outlined by Public Health England (PHE, 2016a). This paper explores how Soja's (1996) concept of spatial theory can be utilised to help understand how school nurses use different types of space to provide emotional support to young people.

\footnotetext{
${ }^{1}$ Extract from screenplay performance of Life and Adventures of Nicholas Nickleby (2002) based on the novel by Charles Dickens (1839).
} 


\section{Spatial Practice}

Soja (1996) has identified three modes of spatial thinking (Baker, 2010) (Table 1). Firstspace (perceived or physical space) consists of physical, concrete spatial forms which can be empirically measured and mapped. Secondspace (conceived or mental space) is expressed in intellectual cognitive terms and is where power and ideology can be located (Baker, 2010). Finally there is Thirdspace, which is the life world of the experiences and draws upon and encompasses the physical and mental spaces. Here creativity flourishes as it extends beyond the other two spaces in scope, substance and meaning and is where socio-political transformation can occur.

\section{Insert Table 1}

\section{Firstspace}

Firstspace is known as 'perceived' space - physical and material space where direct social interactions take place face to face (Brooke, Coyle and Waldron, 2005). It is the space associated with the practicalities of providing support. Traditionally support is provided to young people by school nurses largely within the physical boundary of a school setting, but can occur anywhere where young people gather. It can also refer to other physical resources such as the use of sexual health services.

\section{Accessibility}

As this space is concerned with the practicalities of providing support, the physical environment and 'face to face' contact with young people needs to be regular and consistent. The increasing complexities of young people's emotional health needs, 
suggest that support often needs to be provided consistently and regularly over a period of time (Pryjmachuk et al., 2011). The need for direct human contact (Gray, 2009) and physical 'face to face' accessibility to the school nurse is seen as essential (Owen et al., 2010).

Continuity is a key aspect of Firstspace (Soja, 1996) and so the need to work consistently in a caseload is important in providing continuity and a dependable service. Working consistently within the same 'physical' space (caseload) also provides a sense of ownership and familiar understanding (Kelly et al., 2005) and it takes time to build relationships with schools, young people and their families (Sherwin, 2016). The visibility of the service has historically been a key issue, which is largely due to the relatively small workforce (While and Barriball, 1993; BYC, 2011). To provide support on a practical level school nurses need to be physically visible so young people know who to contact and how to access them. In response to this some school nurses are now based in schools and wearing uniforms to heighten their visibility and raise their profile (Sherwin, 2015).

\section{Secondspace}

Secondspace (conceived) is described by Soja (1996) as being an imaginary intellectual expanse. This can be aligned to the 'practice' of school nursing in providing support and identifies what 'ways of thinking' (thoughts of the mind) influences 'ways of doing' (Royal College of Nursing, 2014). Locating school nursing practice within this space is useful to advocate improvements in social justice for young people through the consideration of better ideas and good intentions. Aspects of school nursing practice such agency and emotional investment within the role are key features of Secondspace. 


\section{Agency}

Agency is often used to describe the levels of power, autonomy and locus of control experienced by an individual(s) (Giddens, 1979; Bourdieu, 2000). Such terms may be determined by the individual's interpretation of how much power or agency they perceive, thereby supporting Soja's (1996) thinking that Secondspace is where one conceives, imagines and interprets. They are also terms associated with a sense of having a voice, which in this context relates to their collective identity as school nurses within the wider nursing and health community. School nurses feel they have suffered from a lack of investment (Chase et al., 2010) and may not feel valued by others (Sherwin, Cross and Holyoake 2014). Research has shown that some school nurses believe they have no power to transform this situation and feel unable to act (Sherwin, 2016). Whilst this may be unintended conduct, it is the human need for ontological security that leads to repetitious acts (or lack of action) by the agent (i.e. the person) that reproduces the structure or outcome itself, and so the perception becomes the norm (Giddens, 1979) and a self-fulfilling prophecy. Wilstrand et al. (2007) suggest that nurses experiencing feelings of frustration and burden can be taken hostage by their own emotions, as they struggle to cope and are left feeling disempowered. Bourdieu (2000) suggests that people's attitudes and values are predisposed to be rooted in past experiences and perceptions. What he terms as 'habitus', is described as competencies gained from upbringing and experiences in the past. Giddens (1979 p.83) purports, that those who passively accept dominant situations are imprisoned within these perspectives. Therefore the answer must lie with the school nurses themselves as being able to self-legitimate leads to power and maximises performativity (Schechner, 2002). 
Indeed, the significant role that school nurses play in supporting the emotional health needs of young people has not gone unrecognised by policy makers and researchers (DH/DfE, 2017; PHE, 2016a; DH, 2012; Chase et al., 2010) but has failed to be translated into actual resources and increased capacity (Godson, 2013a). However, school nurses need to consider individually and collectively about how they view their own imagined self-identity and self-worth to demonstrate a sense of agency as empowerment is key to their practice. How school nurses imagine their self-belief, is fundamental to the progression of the profession, in terms of influencing commissioning services and improving mental health support for young people.

\section{Emotional investment}

Emotional investment is situated in the context of Soja's (1996) definition of Secondspace. Caring is at the heart of nursing practice (NMC, 2015; NHS England, 2016) and encompasses a degree of emotional investment (Gray, 2009). School nurses have expressed how they 'worry' about the vulnerable young people they support emotionally, and that they often take these 'worries' home with them (Sherwin, 2016). Young people can become more vulnerable and experience emotional distress at certain times, such as biological (adolescence), psychological (family or relationship breakdown) or social (changing schools) transition periods with some being more susceptible or complex than others (Appleton, 2016; DH, 2011). Therefore, it can be difficult at times for professionals working with young people to be able to detach their own emotions from these situations.

Empathetic caring within nursing involves emotional and mental as well physical effort and are intrinsically linked (Hudacek, 2004). Bolton (2000) highlights that emotional 
involvement with patients/clients can cause nurses profound anxiety, yet paradoxically it also gives them the greatest job satisfaction. Henderson (2001) describes this emotional investment as an under-appreciated aspect of nursing and so coping with the emotional demands of the role is important. Seeking out collegial support to help to cope, 'bouncing ideas off each other', debriefing with colleagues, access to regular clinical supervision, liaising with safeguarding specialist nurses and seeking help and advice from other specialist services such as CAMHS are important coping strategies for school nurses to adopt.

\section{Thirdspace}

Thirdspace is where creative transformative action is brought to bear drawing together both other spaces (Soja 1996). Thirdspace is entered at any time that one acts within an existing space, thus creating a new and different way of operating within spatial practice (Brooke, Coyle and Walden, 2005). However, care must be taken not to negate the dimensions of Firstspace and Secondspace, but to combine them into a new inspirational hybrid space where potential transformation and change can occur (Baker, 2010).

\section{Developing mutually trusting relationships}

The importance of building effective trusting relationships between the school nurse and young person and vice a versa is well documented (DH/DCSF, 2009; BYC, 2011; DH/DfE, 2017). As registered nurses they can protect confidentiality (unless there is a safeguarding issue) which is valued by young people and helps to build and develop relationships based on respect and trust (BYC, 2011). Transformation is a defining feature of Thirdspace, therefore it is within this 
trusting relationship that change, revolution or reformation can take place (Baker, 2010). Building effective therapeutic relationships is a vital discourse of nursing (Gray, 2009; Hudacek, 2008). Research has highlighted that a mutually trusting and respectful relationship is a key aspect in the provision of support, and to the success in delivering key health promotion messages (Holmstrom, Asplund and Kristiansen 2013). Without a mutual level of trust, any attempt to provide therapeutic interventions such as building self-esteem, listening therapy, or developing coping strategies to deal with anxiety or anger management is unviable and any transformation maybe compromised. However, once the relationship is established, creativity and transformation can allow the young person to move forward.

\section{Role containment versus role diffusion}

There may be a tension in what school nurses feel they could potentially provide as a service and what they are actually able to provide. It appears that is due to a lack of sufficiently qualified staff and reduced financial investment (the exigency of organisational structures) (Sherwin, 2016). Due to reduced capacity, lack of staff and increasing need there are inevitably restrictions i.e. containments on the level of care and support school nurses can offer. Yet conversely at policy level, there is a drive to 'diffuse' the school nurse role yet further into other areas of practice for example, supporting 16-19 year olds (DH/DCSF, 2009) without any additional significant investment (Godson, 2013a; 2013b). This highlights that in Thirdspace school nurses are having to make "wise and prudent practical judgements" (Carr and Kemmis, 1986 p.190) regarding the level of care offered. However, this could result in subversive actions taken by school nurses, on behalf of the young people, 
by working outside of set parameters. This is often described in lay terms "as going the extra mile" which could be depicted as the art or craft of nursing. This is more than just following a set of rules and instructions, but which involves care, intuition and emotion (Edwards, 1998). Hochschild (1983) advocates that nurses, whilst subscribing to the 'rules' of the organisation and maintaining professional norms, are able to move beyond these prescribed 'rules', and can choose to add something extra to the relationship with their patient or client. This can be described as a 'gift' given freely, and sometimes unconsciously without the nurse counting the personal cost to themselves as previously discussed highlighting that spatial areas of practice can merge. Bolton (2000) recognises that as health services increasingly operate within a business model, altruism is becoming more challenging to maintain; yet nurses can be autonomous and will find time to offer extra emotional support when it is needed.

In addition, some school nursing services are now being commissioned by other agencies outside of the NHS. Although this is not a new phenomenon, it does mean school nursing may be commissioned and managed by those from non-health backgrounds. Therefore, being able to measure the impact of service delivery is ever more important to provide evaluative evidence of clinical effectiveness and efficiency to ensure on-going commissioning (Godson, 2013a). Although there may be a difference of opinion between clinicians and managers about what success actually is, as gauging success in terms of measuring improvements in mental health, may be a long-term complex activity.

\section{Making a difference}


School nurses report how they 'make a difference' by providing the support young people require helping them to transform situations; a key feature of Thirdspace (Sherwin, 2016). Johns (2002) suggests that people can only enlighten and transform themselves, yet nurses can support, challenge, inspire and motivate others within this transformation process thus making a difference to people's lives. Making a difference can be intangible yet helping to make life better for someone and witnessing positive change is very rewarding, and it is why nurses do what they do (Hudacek, 2004).

\section{Political transformation}

For nurses working as public health practitioners, there is always a political dimension to their role, albeit it at times it may be pushed to their subconscious (DeBell, 2016). Engaging in political interplay is a key principle of the Specialist Community Public Health (SCPHN) School Nursing qualification, as the programme requires them to operate at a more strategic level to influence public health (NMC, 2004; PHE, 2016b). There is a need for SCPHN school nurses to be politically active and to contribute to policy development by shaping services to help meet their population's needs (Sherwin and Smith, 2009). Thirdspace offers a transformational opportunity for school nurses to engage more agentically at a practical level, and as a corollary courageously, in terms of new ways of working in developing and influencing policy to bring about change. School nurses need to act as proactive leaders to bring about political transformation in terms of influencing health policy. Structure should not be a barrier to action, but a concept that should be embraced and involved in its production (Giddens, 1979). Similarly, any dissonance should be viewed as possibilities for creativity (Johns, 2002) to meet increasing demand. 


\section{Fourthspace}

Soja's (1996) work outlines three elements of spatial practice. However, he urges that his work is used to think differently, and if appropriate to "invent a different term to capture what I am trying to convey" (Soja, 1996 p.2). This paper is not suggesting that there should be different terms to explain his work, because his theory does provide a utilitarian approach in offering a deeper insight into the provision of support within school nursing practice. However, by extending Soja's (1996) typology there is an additional, but as yet uncharted, Fourthspace (virtual) space in which school nurses now operate to provide support to young people (Fig. 1).

\section{Insert Figure 1}

\section{Use of technology}

Fourthspace is where technology and digital media can be used to provide support in a virtual world and can operate alongside other spaces. Modern day society is becoming increasingly immersed in a digitalised and virtual world (Sobande, 2013). Consumer access to information has changed (Savin-Baden et al., 2013), and for today's young people, the use of the internet, social media and digital technology are commonplace. This is generally in a positive manner but online bullying, blackmail, grooming and the use of the dark web is increasingly more common (DH, 2012). Operating online appears to instil a sense of anonymity and 
so young people may engage in activities that position themselves in potentially risky situations, yet for many it is where and how they conduct their social and emotional lives (The Children's Society, 2017). School nurses have a responsibility to find ways of communicating effectively with young people and therefore need to understand and utilise technology to do so (Sobande, 2013). Consequently, providing support can be given through a virtual medium using technology such as text messaging or other social media. It can be used to check if the young person is safe, provide reassurance to them or to arrange a face to face appointment to provide more in-depth support. The social environment fostered by virtual space is often typified by dialogue that is more open and frank (Barak and Gluck-Ofri, 2007), thus allowing school nurses to help identify which young people need further support.

Sobande (2013) purports that using social media can help establish an online school nursing community, thereby reducing feelings of professional alienation, enhance communication and provide support amongst the profession by assisting them to have a wider voice. Communication via social media such as Twitter, can remove historical hierarchal boundaries, as nurses working on the frontline now have access to nurse leaders working at a strategic level. This can result in nurses feeling reinvigorated, having an increased sense of pride, and a feeling of empowerment by communicating online sharing stories and engaging in debate (Sobande 2013). This illustrates how Fourthspace can relate and interact effectively with other space. For example, in Secondspace where a lack of power and agency within school nurses has been identified, the use of Fourthspace could bring the school nurse community together nationally, thus increasing a sense of agency, and provide an opportunity for the community to unite together. 


\section{Conclusion}

Soja's (1996) concept of First, Second and Thirdspace has been utilised to help understand how school nurses provide emotional and mental health support to young people and a new Fourthspace has been identified. Identifying these multiple spaces and understanding how they interact and influence practice, enables school nurses to work practically, in practice and within praxis and highlights how school nurses need to become more empowered and political. Young people who need help in times of adversity, crisis and distress must be able to access the right type and amount of emotional support. Until this is in place there are too many who will continue to experience unhappiness, distress, health inequalities and social injustice just as Charles Dickens described back in 1839.

"What happens when the light first pierces...the dark dampness in which we have waited? We are slapped and cut loose. If we are lucky someone is there to catch us.... and persuade us that we are safe. But are we safe? What happens if, too early we lose a parent? That party on whom we rely for not only everything? Why, are we cut loose again ... and we wonder, even dread... whose hands will catch us now?"2

Table 1: Concepts of space (Soja, 1996)

\begin{tabular}{|c|c|c|}
\hline Firstspace & Secondspace & Thirdspace \\
\hline Physical space & Mental space & Social space \\
\hline Perceived & Conceived & Lived \\
\hline
\end{tabular}

\footnotetext{
${ }^{2}$ Extract from screenplay performance of Life and Adventures of Nicholas Nickleby (2002) based on the novel by Charles Dickens (1839).
} 


\begin{tabular}{|l|l|l|}
\hline Practicalities & Praxis & Practice \\
\hline
\end{tabular}

Figure 1: The provision of support within the spatiality of everyday school nursing practice (Sherwin, 2016).

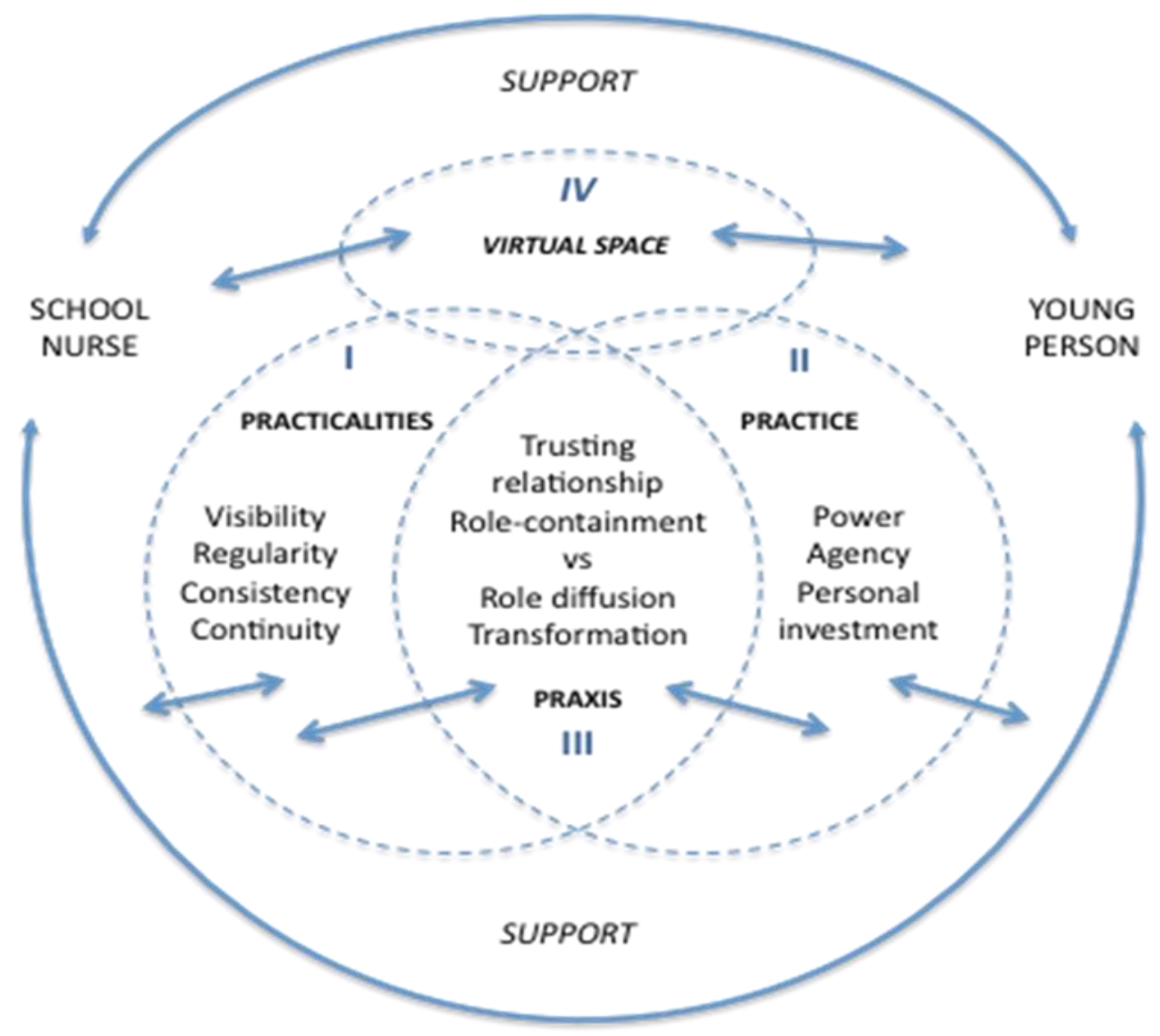




\section{References}

Appleton, J. (2016) Vulnerable children. in DeBell, D. (ed) Public Health for Children. $2^{\text {nd }}$ ed. New York: Taylor Francis Group

Baker, C. (2010) Re-entering the Thirdspace? Re-evaluating Soja's spatial theory in and for the postsecular city. Chester: William Temple Foundation [online]. [Accessed19/4/17].

Available at www.williamtemplefoundation.org.uk/documents/AAG2010-BAKER

Barak, A. and Gluck-Ofri, O. (2007) Degree and reciprocity of self disclosure in online form. Cybersychology and Behaviour, 10 (3), pp. 407-417.

Bolton, S.C. (2000) Who cares? Offering emotion work as a gift in the nursing labour process. Journal of Advanced Nursing, 32 (3), pp. 580-586.

Bourdieu, P. (2000) Outline of a theory of practice. Cambridge: Cambridge University Press.

British Youth Council [BYC](2011) Our school nurse. Young people's views on the role of the school nurse. London: British Youth Council. [online] [Accessed 1/7/18] Available at .www.byc.org.uk

Brooke, R., Coyle, D. and Walden, A. (2005) Finding a space for professional development: Creating Thirdspace through after school writing clubs. Language Arts, 82 (95), pp. 367-377.

Carr, W. and Kemmis, S. (1986) Becoming Critical. Education, knowledge and action research. Lewes: Falmer

Chase, E, . Chalmers,H., Warwick, I., Thomas, F., Hollingworth, K. and Aggleton, P. (2010) Promoting the health of children and young people through schools: The role of the nurse. London: Thomas Corum Unit.

Debell, D. (ed) (2016) Public Health for Children. $2^{\text {nd }}$ ed. New York: Taylor Francis Group

Department of Health (2011) No health without mental health. London: Department of Health.

Department of Health (2012) Getting it right for children, young people and families. Maximising the contribution of the school nursing team: Vision and call to action. London: Department of Health. 
Department of Health and Department for Education (2017) Transforming children and young people's mental health provision: A Green Paper. London: DH. DfE.

Department of Health and Department of Children, Schools and Families (2009) Healthy Child Programme 5-19 years. London: Department of Health

Edwards, S. D. (1998) Philosophical issues in nursing. London: Palgrave.

Giddens, A. (1979) Central problems in social theory: Action, structure and contradiction in social analysis. London: Macmillian Press.

Godson, R. (2013a) Making sure that local authorities are aware of the school nurses' role. British Journal of School Nursing, 8(7), pp. 346-348.

Godson, R. (2013b) Funding for school nursing services. British Journal of School Nursing, 8(4) p. 204.

Gray, B. (2009) The emotional labour of nursing. Defining and managing emotions in nursing work. Nurse Education Today, 29(2), pp. 168-175.

Hagell, A., Coleman, J., and Brooks, F (2015) Key data on adolescence. London: Association for Young people's Health.

Henderson, A. (2001) Emotional labour and nursing: An underappreciated aspect of caring work. Nursing Inquiry, 8(2), pp. 130-138.

Hochschild, A. (1983) The managed heart: Commercialisations of human feeling. Berkeley: University of California Press.

Holmstrom, M.R., Asplund, K. and Kristiansen, L. (2013) Promoting a relationship based health practice: A challenge for school nurses. British Journal of School Nursing, 8(1), pp. 30-38.

Hudacek, S.S. (2004) Making a difference: Stories from the point of care. Volume 2. Indianapolis: Sigma Theta Tau International

Hudacek, S.S. (2008) Dimensions of Caring: A qualitative analysis of nurses' stories. Journal of Nursing Education, 47(93), pp. 124-129.

Johns, C. (2002) Guided reflection: Advancing practice. Oxford: Blackwell Publishing.

Kelly, N., Greaves, C., Buckland, L. and Rose, J. (2005) School nurses: well placed to address challenging behaviour. Community Practitioner, 78(3), pp. 88-92.

NHS England (2016) Leading Change: Adding Value [online] [Accessed 4/7/18] Available at https://www.england.nhs.uk/leadingchange

Nursing and Midwifery Council (2004) Standards of Proficiency for Specialist Community Public Health Nurses. London: NMC. 
Nursing and Midwifery Council (2015) The Code: Professional standards of practice and behaviour for nurses and midwives. London: NMC

Owen, J., Carroll, C., Cooke, J., Formby, E., Hayter, M., Hirst, J., Lloyd Jones, M., Stapleton, H., Stevenson, M and Sutton, A. (2010) School linked sexual health services: a survey and systematic review concerning current models, effectiveness, cost effectiveness and research opportunities. Health Technology Assessment, 14 (30), pp. 1-223.

Pryjmachuk,S., Graham, T., Haddad, M. and Tylee, A. (2011) School nurses' perspectives on managing mental health problems in children and young people. Journal of Clinical Nursing, 21(5), pp. 850-859.

Public Health England (2016a) School age years 5-19. High impact area 1: Resilience and emotional wellbeing. London: PHE.

Public Health England (2016b) Healthy Child Programme 0-19: Health Visiting and School Nursing Commissioning. London: PHE [online] [Accessed 21/6/18] Available at https://www.gov.uk/government/publications/healthy-child-programme-0-to-19health-visitor-and-school-nurse-commissioning

Public Health England (2018) Rapid review on safeguarding to inform the Healthy Child Programme 5 to 19. London: PHE [online] [Accessed 21/6/18] Available at https://assets.publishing.service.gov.uk/government/uploads/system/uploads/attach ment data/file/680391/Rapid Review on Safeguarding to Inform the Healthy Child P rogramme 5 to 19.

Ravenna, J. and Cleaver, K. (2016) School nurses' experiences of managing young people with mental health problems: a scoping review. The Journal of School Nursing. 32(1), pp.58-70.

Royal College of Nursing (2014) Defining nursing. London: RCN.

Savin-Baden, M., Tombs, G., Burden, D. and Wood, C. (2013) "It's almost like talking to a person: Student disclosure to pedagogical agents in sensitive settings. International Journal of Mobile and Blended Learning, 5(2), pp. 78-93

Schechner, R. (2002) Performance studies: An introduction. London: Routledge

Sherwin, S. (2016) Performing school nursing: Narratives of providing support to children and young people. Community Practitioner. April pp.30-34

Sherwin, S. (2015) To wear or not to wear? That is the question: Should school nurses wear uniform? British Journal of School Nursing, 10(3) pp.148-149.

Sherwin, S. and Smith, M. (2009) School nursing and school health practice. in Thornbory, G. (ed)) Public Health Nursing: A textbook for health visitors, school nurses and occupational health nurses. Oxford: Wiley Blackwell. pp. 126-152. 
Sherwin, S., Cross, V. and Holyoake, D. (2014) The pride and the passion: Poetic representations of school nursing practice. British Journal of School Nursing, 9(2), pp. 89-94.

Sobande, M. (2013) Connecting and driving school nursing through social media. British Journal of School Nursing, 8(4), pp. 186-189.

Soja, E. (1996) Thirdspace. Journeys to Los Angeles and other real and imagined spaced. Malden: Blackwell.

The Children's Society (2017) The Good Childhood Report. 2017. London: The Children's Society.

While, A.F. and Barriball, K.C. (1993) School Nursing: History, present practices and possibilities reviewed. Journal of Advanced Nursing, 18(8), pp. 1202-1211.

Wilstrand,C., Lindgren,B., Gilje, F., and Olofsson, B. (2007) Being burdened and balancing boundaries; a qualitative study of nurses caring for patients who self harm. Journal of Psychiatric and Mental Health Nursing, 14(1), pp. 72-78. 